\title{
Effect of Rumen Fluid Dosage and Fermentation Time on Dissolved Protein Levels of Vegetable Waste Silage for Vannamei Shrimp Feed
}

\author{
Brenda Munyiva $^{1}$, Wahu Oyaya ${ }^{2}$, Mumbi Wanjiku Koech ${ }^{2}$ \\ ${ }^{1}$ Faculty of Agriculture, University of Nairobi, Kenya \\ ${ }^{2}$ Faculty of Agriculture, Jomo Kenyatta University of Agriculture and Technology, Kenya
}

\begin{abstract}
Specifically, the goal of this research was to evaluate the dissolved protein content of vegetable waste generated during the incubation of rumen fluid for use in (Whiteleg) vannamei shrimp diet. The results of the analysis of the degree of protein hydrolysis of vegetable waste treated with the addition of rumen fluid enzymes and different fermentation times of rumen fluid revealed that the addition of rumen fluid enzymes and different fermentation times of rumen fluid had a statistically significant effect (p0.05) on the degree of protein hydrolysis of vegetable waste. But there was no significant difference in the length of fermentation time or the interaction between the dosage of rumen fluid and the length of time ( $p>0.05)$ between the two groups. Duncan's test of rumen fluid dosage revealed that the degree of hydrolysis at a 1 percent dose was considerably greater ( $\mathrm{p} 0.05)$ than at 2 percent and 3 percent doses, and that the degree of hydrolysis at a 3 percent dose was significantly lower than at 2 percent.
\end{abstract}

Keywords: Degree of Hydrolysis, Vegetable Waste, Rumen Fluid

Received : September 11, 2021

Received in Revised: September 27, 2021

Accepted: October 3, 2021

\section{Introduction}

In addition to being a high-quality and plentiful source of feed raw materials, vegetable waste has the potential to be utilized as an affordable source of feed raw materials for protein sources of vegetable origin due to its high protein content and abundance. It is necessary to use cellulosic bacteria in a biological process in order to utilize vegetable waste because the protein derived from vegetable waste is difficult for fish to digest because it is coated with a layer of cellulose (Torgbo \& Sukyai, 2018; Basu et al., 2018). This means that a biological process involving cellulosic bacteria must be used.

The formation of the structure and functioning activities of the body in all living things necessitates the presence of protein as a critical molecule. Proteins are made up of chains of amino acids that are joined together by peptide bonds to create a variety of complicated structures (Damodaran \& Parkin, 2017; Salwiczek et al., 2012). When peptide bonds are broken, the protein hydrolysis process is carried out in order to transform protein into a more digestible form, such as amino acids and peptides, which may then be more readily absorbed by the body.

Protein hydrolysis produces low molecular weight peptides, typically consisting of two to four amino acids, which are then excreted in the urine. Factors that influence the pace at which enzymes and substrates hydrolyze are discussed. It is possible to create a protein hydrolyzate that contains 18-20 amino acids if the hydrolysis procedure is carried out properly. 
The use of cellulolytic bacterial inoculum in the biological treatment of vegetable waste as an alternative feed source for vannamei shrimp is very significant in enhancing the quality of the waste product. By leveraging the services of microorganisms, particularly cellulolytic bacteria, efforts are being undertaken to improve the nutritional value of vegetable waste. Agricultural waste is anticipated to be loosening the lingo-cellulose and lingo-hemicellulose complex linkages via biotechnology engineering utilizing cellulolytic bacterial isolates derived from cow rumen fluid, according to expectations.

This technique is more practical since it just requires the spreading of the bacterial inoculum on the vegetable waste substrate to get the desired results. The amount of dissolved protein in shrimp feed raw materials is one of the indicators used to evaluate the quality of the feed raw materials. It is possible to use the dissolved protein content directly since it is the product of enzyme synthesis from vegetable waste. As a result, it is essential to undertake this study in order to evaluate the activity of natural enzymes that hydrolyse vegetable waste.

\section{Methods}

Tools and materials utilized in this research included vegetable waste, cow rumen fluid, aluminium foil for use as a media container, cotton cloth used as a coarse-rumen fluid filter, a thermometer, litmus paper, and centrifugation, among other things. Cow rumen fluid is obtained from the contents of the cow's rumen via filtration (using a cotton cloth to filter the fluid) and storage under refrigeration conditions. It was centrifuged at $10,000 \mathrm{~g}$ for ten minutes at $40^{\circ} \mathrm{C}$ in order to separate the supernatant from the cells and their contents, which was then used to isolate the microbial cells. A crude enzyme source was then extracted from the supernatant (Lee et al. 2000).

Mustard greens, cabbage, kale, and carrots were among the vegetables discarded in the research, accounting for 25 percent of total vegetable waste produced. After grinding the vegetable waste, it is combined with rumen fluids and molasses in the appropriate amount for the treatment, and the silage is then fermented in an anaerobic environment until it is ready for consumption (not oxygenated).

\section{Observed Variables}

The determination of the dissolved protein level of the feed was completed at the conclusion of the research. $1.5 \mathrm{~mL}$ of 5 percent trichloro acetate is added to $0.5 \mathrm{~g}$ of hydrolysed vegetable waste silage, and the crude enzyme protease reaction is halted with $1.5 \mathrm{~mL}$ of 5 percent trichloro acetate. The mixture is allowed to cool to room temperature. Afterwards, $3 \mathrm{~mL}$ of Tris $\mathrm{HCl} \mathrm{pH} 6.5$ solution was added, and the mixture was centrifuged at 10,000 rpm for 20 minutes. The dissolved protein content of vegetable waste was determined using the supernatant produced from the fermentation process.

\section{Results and Discussion}

\section{Degree of Protein Hydrolysis and Dissolved Protein Level}

Table 1 shows the findings of an investigation on the degree of protein hydrolysis of vegetable waste treated with rumen fluid enzymes and various lengths of fermentation time, which was carried out over a period of three months. After doing a study of the degree of protein hydrolysis, the researchers discovered that the amount of rumen fluid administered had a statistically significant impact (p0.05) on the degree of protein hydrolysis.

The length of time for fermentation and the interaction between the dosage of rumen fluid and the length of time showed no significant impact ( $p>0.05$ ), while the amount of vegetable 
waste had a significant effect ( $p>0.05)$. Duncan's rumen fluid dose test revealed that the degree of hydrolysis at 1 percent dose was significantly higher (p0.05) than the degrees of hydrolysis at 2 percent and 3 percent doses, but that the degree of hydrolysis at 3 percent dose was significantly lower than the degree of hydrolysis at 2 percent.

Table 1. Results of the analysis of the degree of hydrolysis

\begin{tabular}{|c|c|}
\hline $\begin{array}{c}\text { Rumen Fluid } \\
\text { Dosage }\end{array}$ & $\begin{array}{c}\text { Degree of hydrolysis of } \\
\text { vegetable waste }(\%)\end{array}$ \\
\hline $1 \%$ & $18,76 \pm$ \\
\hline $2 \%$ & $12,31 \pm$ \\
\hline $3 \%$ & $9,83 \pm$ \\
\hline
\end{tabular}

The highest degree of protein hydrolysis was achieved with a 1 percent $/ \mathrm{kg}$ rumen fluid dose and a fermentation time of 4 days when compared to other treatments. This was achieved due to the rumen fluid dose and fermentation time, which were able to hydrolyse vegetable waste by simplifying complex compounds into simpler compounds, allowing them to be used directly in the fermentation process.

Enzymes are produced by bacteria during the fermentation process, which are responsible for breaking down complex molecules into simpler ones. Furthermore, the enzymes cellulase, amylase, protease, xylanase, mannanase, and phytase may be found in the rumen fluid of ruminants. Amylase, xylanase, avicelase, -D-glucosidase, -L-arabinofuranosidase, D-glucosidase, and -D-xylosidase are carbohydrate-digesting enzymes found in rumen fluid. Amylase, xylanase, avicelase, -D-glucosidase, -L-arabinof It has been discovered that rumen fluid contains the enzymes cellulase, xylanase, mannanase, amylase, protease, and phytase, which are capable of hydrolysing local feed ingredients, and that the inclusion of local bovine rumen fluid enzymes in feed increases the digestibility of broiler chicken feed.

\section{Dissolved Protein}

Using soluble protein analysis, it was discovered that the treatment dosage of rumen fluid, as well as the incubation duration and the interaction between the two, had a statistically significant impact (p0.05) on dissolved protein. While the results of Duncan's additional test showed that the 1 percent treatment dose and the incubation time of 4 days were different from other treatments, the 1 percent treatment dose and 6-day incubation were the same as the 2 percent dose for 4-day incubation, and the 2 percent incubation dose was 6 days, but different from the treatment. It was the same as the treatment with a 3 percent dosage of incubation for four days, but it was different from the treatments with a 3 percent dose of incubation for six days.

The therapy with $1 \%$ 8-day incubation was distinct from all other treatments with $1 \%$ 10-day incubation, including 2 percent for 8-day incubation, 2 percent for 10-day incubation, 3 percent for 8-day incubation, and 3 percent for 10-day incubation, among others. When it comes to incubation time, a treatment dosage of 3 percent for 8 days is the same as a treatment dose of 3 percent for 10 days incubation, but the treatment dose is different.

To the extent that the dosage of rumen fluid utilized is sufficient and the fermentation period is prolonged, the amount of soluble protein generated increases, up to the limit of the dose and the length of fermentation. When compared to the other treatments, the treatment with a 3 percent $/ \mathrm{kg}$ rumen fluid dosage and a fermentation period of 10 days had the greatest soluble protein value of 32.58 percent. 
Many factors affect the hydrolysis of complex feed, including the kind and concentration of enzymes used, the parameters of the substrate, the ambient temperature, and the pace at which the substrate is mixed. Inversely proportional is the relationship between the degree of protein hydrolysis and the amount of dissolved protein present; the greater the degree of protein hydrolysis, the lower the amount of dissolved protein present (de Oliveira et al., 2015; e Silva \& Silveira, 2013).

This is because the degree of protein hydrolysis is related to the crude protein of vegetable waste, where the degree of hydrolysis is obtained by subtracting the final crude protein from the initial crude protein. The final crude protein is divided by the original crude protein, such that if the final crude protein is high, the degree of hydrolysis of the protein acquired is low, but the amount of soluble protein produced is large (Angelidis et al., 2021; le et al., 2008).

\section{Conclusion}

The findings of this research support the hypothesis that the dosage of rumen fluid had a statistically significant impact (p0.05) on the degree of protein hydrolysis of vegetable waste, which was confirmed by the degree of protein hydrolysis analysis. A significant impact (p0.05) was found to exist for the length of fermentation time as well as the interaction between the dosage of rumen fluid and the length of fermentation time. Duncan's rumen fluid dosage test revealed that the degree of hydrolysis at a one percent dose was substantially greater (p0.05) than the degrees of hydrolysis at two percent and three percent doses, respectively. However, the dosage at 3 percent was considerably lower than the dose at 2 percent.

\section{References}

Angelidis, A. E., Crompton, L., Misselbrook, T., Yan, T., Reynolds, C. K., \& Stergiadis, S. (2021). Equations to predict nitrogen outputs in manure, urine and faeces from beef cattle fed diets with contrasting crude protein concentration. Journal of Environmental Management, 295, 113074.

Basu, A., Vadanan, S. V., \& Lim, S. (2018). A novel platform for evaluating the environmental impacts on bacterial cellulose production. Scientific reports, 8(1), 18.

Damodaran, S., \& Parkin, K. L. (2017). Amino acids, peptides, and proteins. In Fennema's food chemistry (pp. 235-356). CRC Press.

de Oliveira, C. F., Corrêa, A. P. F., Coletto, D., Daroit, D. J., Cladera-Olivera, F., \& Brandelli, A. (2015). Soy protein hydrolysis with microbial protease to improve antioxidant and functional properties. Journal of Food Science and Technology, 52(5), 2668-2678.

e Silva, A. C. S., \& Silveira, J. N. (2013). Correlation between the degree of hydrolysis and the peptide profile of whey protein concentrate hydrolysates: effect of the enzyme type and reaction time. American Journal of Food Technology, 8(1), 1-16.

Le, P. D., Aarnink, A. J. A., Jongbloed, A. W., Van der Peet-Schwering, C. M. C., Ogink, N. W. M., \& Verstegen, M. W. A. (2008). Interactive effects of dietary crude protein and fermentable carbohydrate levels on odour from pig manure. Livestock Science, 114(1), 48-61. 
Salwiczek, M., Nyakatura, E. K., Gerling, U. I., Ye, S., \& Koksch, B. (2012). Fluorinated amino acids: compatibility with native protein structures and effects on proteinprotein interactions. Chemical Society Reviews, 41(6), 2135-2171.

Torgbo, S., \& Sukyai, P. (2018). Bacterial cellulose-based scaffold materials for bone tissue engineering. Applied Materials Today, 11, 34-49 